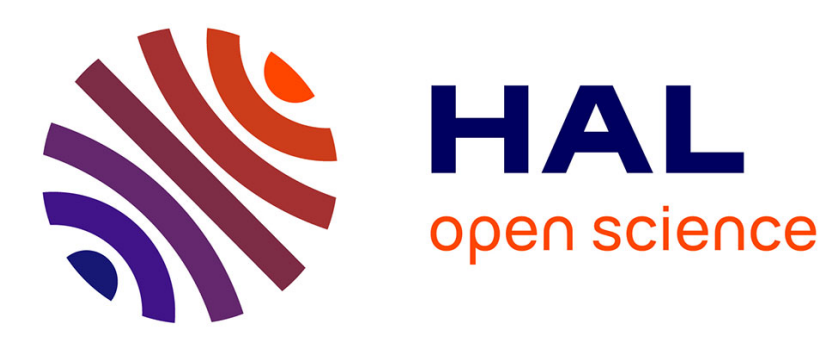

\title{
Vaulting quantification during level walking of transfemoral amputees
}

Xavier Drevelle, Coralie Villa, Xavier Bonnet, Isabelle Loiret, Pascale Fode, Hélène Pillet

\section{- To cite this version:}

Xavier Drevelle, Coralie Villa, Xavier Bonnet, Isabelle Loiret, Pascale Fode, et al.. Vaulting quantification during level walking of transfemoral amputees. Clinical Biomechanics, 2014, 29, pp.679-683. 10.1016/j.clinbiomech.2014.04.006 . hal-01088699

\section{HAL Id: hal-01088699 \\ https://hal.science/hal-01088699}

Submitted on 13 Jan 2015

HAL is a multi-disciplinary open access archive for the deposit and dissemination of scientific research documents, whether they are published or not. The documents may come from teaching and research institutions in France or abroad, or from public or private research centers.
L'archive ouverte pluridisciplinaire HAL, est destinée au dépôt et à la diffusion de documents scientifiques de niveau recherche, publiés ou non, émanant des établissements d'enseignement et de recherche français ou étrangers, des laboratoires publics ou privés. 


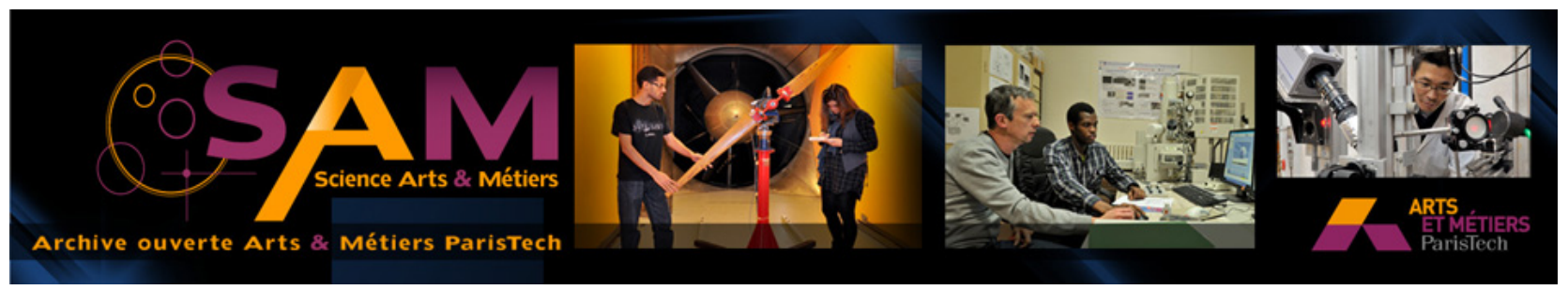

Science Arts \& Métiers (SAM)

is an open access repository that collects the work of Arts et Métiers ParisTech researchers and makes it freely available over the web where possible.

This is an author-deposited version published in: http://sam.ensam.eu

Handle ID: .http://hdl.handle.net/10985/9009

\section{To cite this version :}

Xavier DREVELLE, Coralie VILLA, Xavier BONNET, Isabelle LOIRET, Pascale FODE, Hélène PILLET - Vaulting quantification during level walking of transfemoral amputees - Clinical Biomechanics - Vol. 29, p.679-683 - 2014 


\title{
Vaulting quantification during level walking of transfemoral amputees
}

\author{
Xavier Drevelle ${ }^{\mathrm{a}, *}$, Coralie Villa ${ }^{\mathrm{b}}$, Xavier Bonnet ${ }^{\mathrm{c}}$, Isabelle Loiret ${ }^{\mathrm{d}}$, Pascale Fodé ${ }^{\mathrm{a}}$, Hélène Pillet ${ }^{\mathrm{b}, * *}$ \\ a Institution Nationale des Invalides Centre d'Etude et de Recherche sur l'Appareillage des Handicapés, BP 50719, 57147 Woippy Cedex, France \\ b Arts et Metiers ParisTech, LBM, 151 boulevard de l'Hôpital, 75013 Paris, France \\ c PROTEOR, 6 rue de la redoute, 21250 Seurre, France \\ ' Centre de médecine physique et de réadaptation Louis Pierquin IRR-UGECAM Nord-Est 75, Boulevard Lobau, CS 34209, 54042 Nancy Cedex, France
}

\section{Keywords:}

Biomechanics

Gait analysis

Transfemoral amputees

Vaulting

Kinematics

Kinetics

\begin{abstract}
A B S T R A C T
Background: Vaulting is a gait compensatory mechanism used by transfemoral amputees to assist toe clearance during the prosthetic swing phase. It is defined by a plantar flexion of the contralateral ankle during the single-limb support phase. The aim of the study is to propose a method to quantify vaulting of transfemoral amputees.

Methods: 17 transfemoral amputees and 28 asymptomatic subjects participated in the data collection. Kinematics and kinetics of the whole body were recorded while subjects were walking on a level surface. Biomechanical gait analysis was focused on a reduced set of parameters linked to the contralateral ankle, the contralateral knee and the trajectory of the center of pressure. The patients were classified in two groups: with or without vaulting using video recordings. Differences between both groups and the control group were analyzed.

Findings: A higher generated ankle power was found during the single support phase of the contralateral limb of transfemoral amputees presenting vaulting. These subjects presented also a higher dissipated knee flexion power before the peak in ankle flexion power. The trajectory of the center of pressure was also modified by the vaulting. Interpretation: Vaulting for transfemoral amputees is characterized by a propulsive plantar flexion at the contralateral ankle. Quantifying the ankle flexion power during the contralateral single support phase will help in understanding vaulting.
\end{abstract}

\section{Introduction}

Transfemoral amputees have to pay particular attention to foot clearance during the prosthetic swing phase. Catching of the prosthetic foot and the floor can result in a fall. To reduce the risk of falling, transfemoral amputees develop compensatory strategies which could lead to gait abnormalities, vaulting is one of them. Smith et al. (2002) described it as "a premature midstance plantar flexion by the sound limb which assists toe clearance of the prosthetic limb by lifting the body". Among possible causes are: an overly long prosthesis, a too posterior alignment of the prosthesis, an excessive prosthetic knee resistance to flexion or a patient habit due to fear of falling (Smith et al., 2002). It occurs between the initial and the middle of the prosthetic swing phase after body weight transfer to the contralateral limb during the contralateral single support. The plantar flexion of the contralateral ankle helps the patient to lift his whole body. Therefore, it increases the distance between the prosthetic foot extremity and the walking surface

\footnotetext{
* Correspondence to: X. Drevelle, 47 rue de l'échat, CS 20045, 94048 Creteil Cedex, France. ** Correspondence to: H. Pillet, Arts et Métiers ParisTech, Laboratoire de Biomécanique, 151 Boulevard de l'Hôpital, 75013 Paris, France.

E-mail addresses: xavier.drevelle@invalides.fr (X. Drevelle), helene.pillet@ensam.eu (H. Pillet).
}

to avoid collision with the ground. Long term vaulting could cause overloading of the contralateral forefoot which could lead to pain at the metatarsal head or to the sinus tarsi syndrome. Other biomechanical consequences could be higher energy expenditure compared to asymptomatic subjects (Waters and Mulroy, 1999) and asymmetric loading distribution with higher ground reaction forces on the intact limb compared to the prosthetic limb (Engsberg et al., 1993). It could also lead to an increase of ankle, knee and hip moments at the contralateral limb compared to asymptomatic subjects (Nolan and Lees, 2000).

As it is considered as a gait abnormality, clinicians seek to correct vaulting during rehabilitation. Evaluation during a clinical exam is mainly based on naked eye observations. The plantar flexion of the ankle cannot be identified immediately with the naked eyes due to the difficulty to observe a small angle. So the visual criterion is a premature rise of the contralateral heel during the single support, which is caused by vaulting. This qualitative analysis does not allow a quantification of the vaulting. However, a quantitative analysis of this abnormality would be very useful for the understanding of involved mechanisms and the assessment of the efficiency of rehabilitation. Therefore, there is a need to propose one or some relevant and reliable parameter(s) able to quantify vaulting during clinical follow-up of patients with amputation.

Few studies have analyzed vaulting. Subjects with leg length discrepancy have shown an increase of the ankle plantar flexion of the 
short limb during the single support to ensure toe clearance which could be assumed as vaulting (Walsh et al., 2000). More recently, ankle flexion power was used to characterize vaulting for children suffering from Charcot-Marie-Tooth disease (Ferrarin et al., 2012). Besides, as vaulting is an abnormality occurring during the single support phase, center of pressure ( $\mathrm{CoP}$ ) displacement under the contralateral foot should be affected. Abnormal CoP displacement patterns have already been reported for both contralateral and prosthetic feet for transfemoral amputees (Schmid et al., 2005). However, no correlations were made with gait deviations. To the authors' knowledge, there is no study concerning quantification of vaulting for transfemoral amputees.

The aim of the present study is to quantify vaulting for transfemoral amputees using several gait parameters. Quantitative comparisons between amputees who vault and amputees who did not vault will be made.

\section{Methods}

17 subjects with transfemoral amputation participated in data collection (16 male, 1 female; 37 yrs SD 10; height $1.74 \mathrm{~m}$ SD 0.09; mass $76 \mathrm{~kg}$ SD 10). 16 subjects were fitted with stance and swing phase controlled knees and energy-storing prosthetic foot; 1 subject was equipped with a pneumatic polyaxial knee and an energy-storing prosthetic foot. The mean amputation duration was 10.1 yrs (SD 9). Asymptomatic subjects were recruited to form a control (C) group (17 male, 11 female; age 43 yrs SD 18; height 1.74 m SD 0.10; mass $70 \mathrm{~kg}$ SD 14). The protocol was approved by the local ethics committee and written informed consent was obtained from all participants.

The protocol was detailed in a previous study (Pillet et al., 2010). All subjects were fitted with 54 reflective markers following a pattern derived from the ISB recommendations (Wu et al., 2002; Wu et al., 2005). Kinematics of the whole body were recorded at $100 \mathrm{~Hz}$ with an 8-camera motion analysis system (Vicon V8i, Vicon Motion Systems, Oxford, UK). Subjects were asked to walk at a comfortable selfselected speed on a level surface instrumented with two force platforms (AMTI, $100 \mathrm{~Hz}$, Advanced Mechanical Technology Inc, Watertown, USA). A trial was considered as successful when each foot was placed centrally on a force plate during stance. Five successful trials were recorded. A personalized inertial model of the body for each subject was built using a static trial and a pair of photographs used to adjust the model's geometry (Pillet et al., 2010). The model included feet, shanks, thighs, pelvis, trunk, head, upper arms and forearms.

The spatio-temporal parameters, segmental and articular kinematics and kinetics of the lower limbs were computed from the data of the five successful trials. The biomechanical analysis of vaulting was focused on a reduced set of parameters. It was hypothesized that vaulting is related to motion in the sagittal plane only. Thus, all chosen parameters were computed from the average curves of angles, moments and powers in the sagittal plane. As vaulting is defined by a plantar flexion movement, the minimal flexion angle of the contralateral ankle was computed during the contralateral single support phase (AFlexAng) (Fig. 1). Positive values define dorsal flexion whereas negative values define plantar flexion. As a propulsive movement occurs during vaulting, flexion power at the contralateral ankle was computed as the product between the internal flexion moment and the flexion angular speed at the contralateral ankle (Sadeghi et al., 2001). The power was normalized by subject's mass and was expressed in $\mathrm{W} \cdot \mathrm{kg}^{-1}$. Positive values define a generated power whereas negative values define a dissipated power. The maximum value of the contralateral ankle flexion power during the single support phase (AFlexPwr) of the contralateral limb was computed (Fig. 1) (Ferrarin et al., 2012). In order to analyze the compensatory mechanisms at the contralateral knee, the maximal knee flexion angle (KFlexAng) and the minimal knee flexion power between $0 \%$ and $40 \%$ of gait cycle (KFlexPwr) were also computed (Fig. 1). As vaulting leads
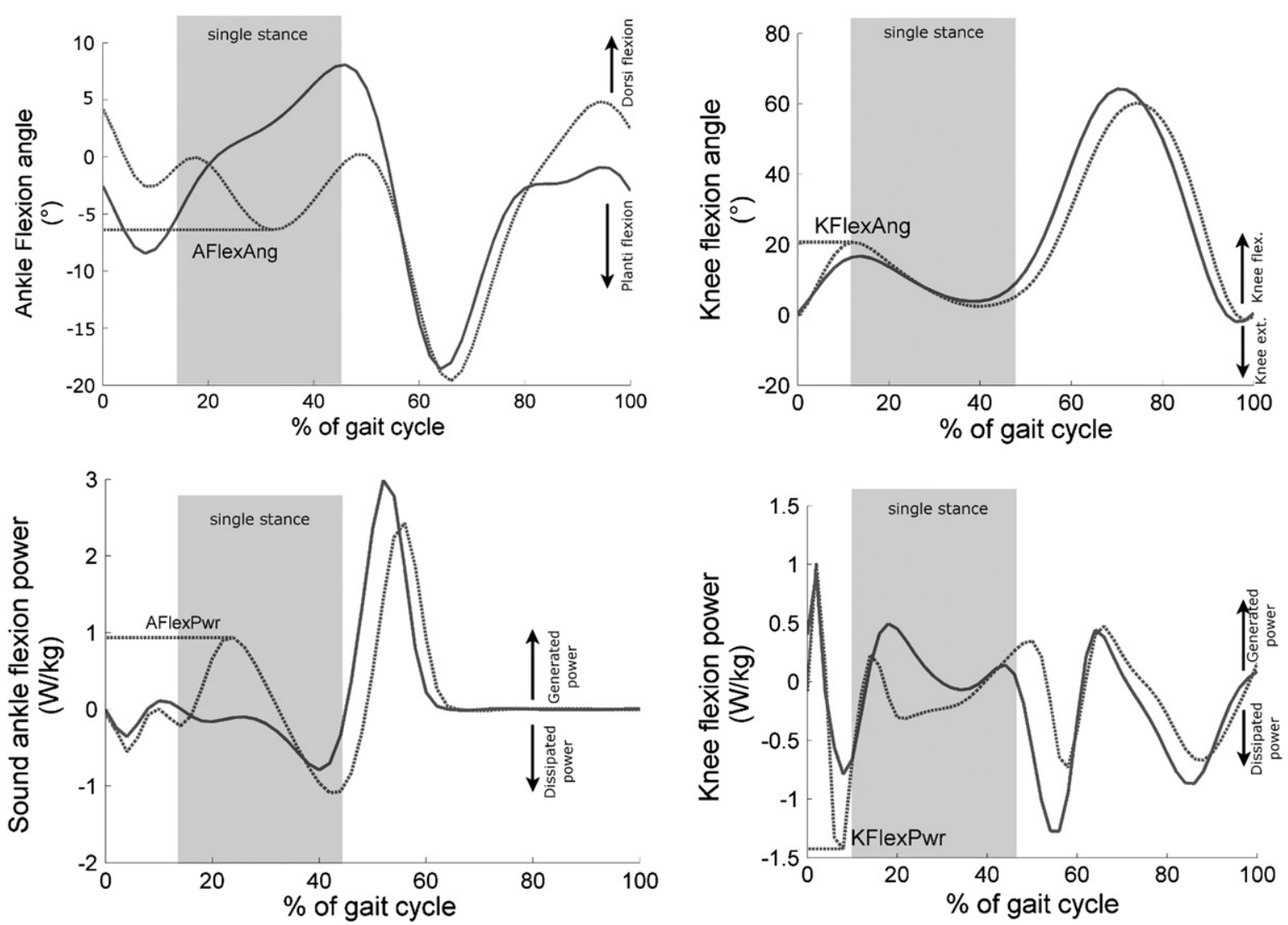

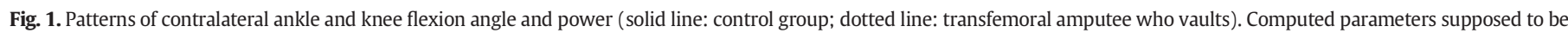
linked to vaulting are represented on the graphs. 
to a premature contralateral heel rise, a modification of the displacement of the CoP can be expected. Therefore, the longitudinal position of the CoP was computed in the contralateral foot anatomical frame (Fig. 2). The origin of the frame was defined by the middle of the first and fifth metatarsal heads (called in the current study "center of the metatarsal heads"). The X-axis was defined by the line joining the calcaneus to the center of the metatarsal heads. Position was normalized by the distance between the calcaneus and the center of the metatarsal heads. The mean position of the CoP during the stance phase along longitudinal axis was computed (CoPX) (Fig. 3). A positive value defined an average position of the CoP in front of the center of the metatarsal heads whereas a negative value defined an average position between the calcaneus and the center of the metatarsal heads $(-100 \%$ means that CoP is placed at the calcaneus whereas a position equals to $0 \%$ means that $\mathrm{CoP}$ is placed at the center of the metatarsal heads). A temporal parameter linked to the CoP trajectory was also defined. CoP\% was the instant of the gait cycle when $\mathrm{CoP}$ longitudinal position became equal to the average CoP position (CoPX) (Fig. 3).

Transfemoral amputees were screened for gait deviations (such as vaulting, hip elevation, circumduction, trunk bending ...) through a review of video recordings of front and side views of each trial. In the current study, vaulting was the only gait deviation of interest. According to the expertise of medical experts, amputees were classified in two groups regarding observations of vaulting. Visual criterion was a premature heel rise during the contralateral single stance phase. Transfemoral amputees who appeared to vault on video recordings formed the vaulting $(\mathrm{V})$ group. Patients who did not appear to vault on video recordings constituted the no-vaulting (NV) group. For each parameter, statistical differences between the three groups (C: Control group, V: Vaulting group, NV: Novaulting group) were analyzed using a Mann-Whitney test ( $\alpha=0.05$ ).

\section{Results}

\subsection{Clinical observations of vaulting}

Resulting from the review of the video recordings, 6 amputees did not appear to vault on video recordings, so they formed the NV group.

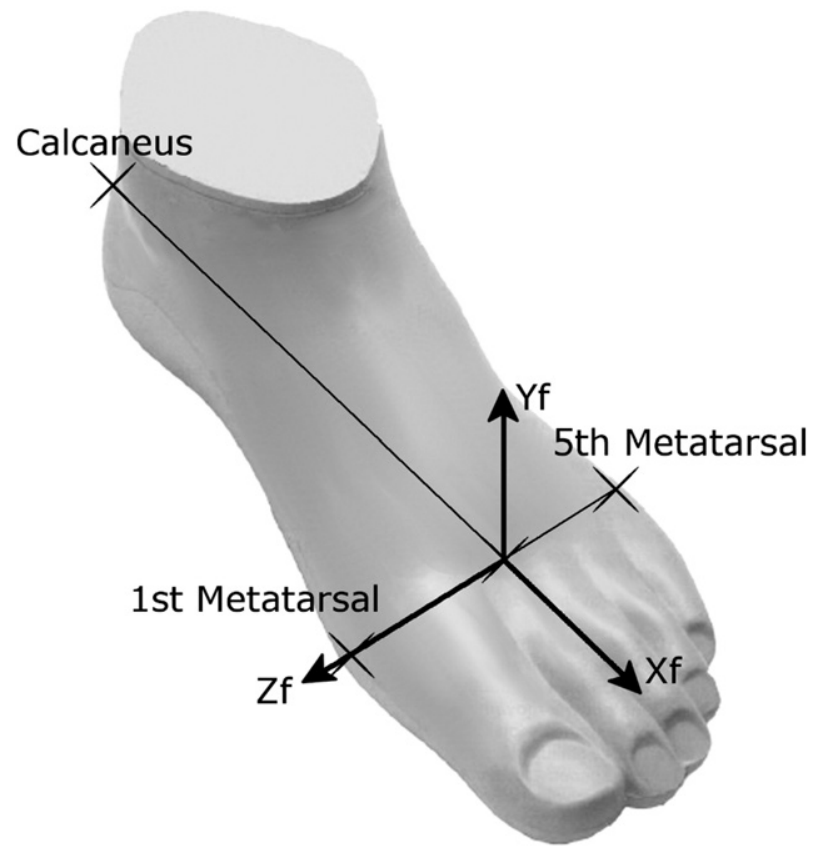

Fig. 2. Description of the anatomical frame of the foot. Origin is the center of the metatarsa heads. Xf is the vector joining the calcaneus to the middle of the 1st and 5th metatarsal heads. $\mathrm{Zf}$ is the vector joining the $1 \mathrm{st}$ and 5 th metatarsal heads. Yf is obtained from the cross-product of Zf and Xf.

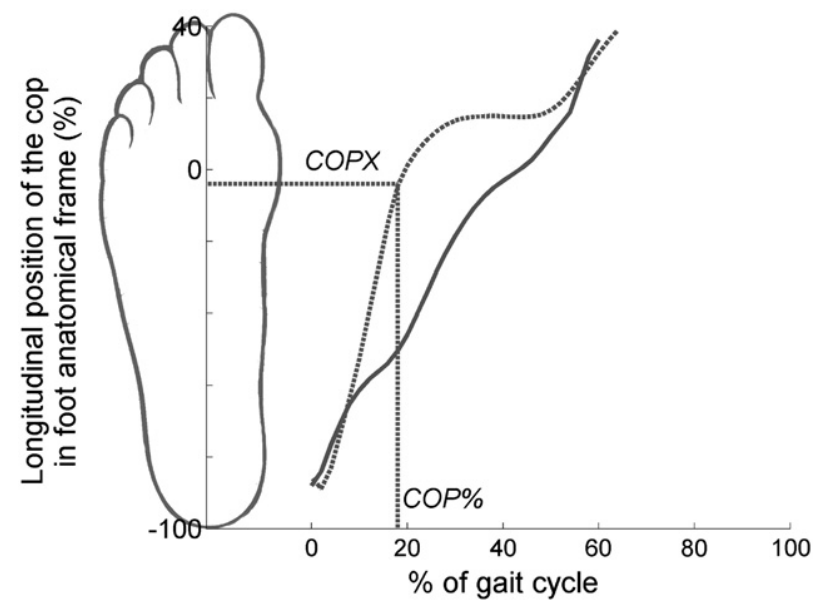

Fig. 3. CoP displacement along the $\mathrm{X}$-axis of the anatomical foot frame vs time (solid line: control group; dotted line: transfemoral amputee subject who vaults). Displacement was normalized with respect to the distance between the calcaneus and the center of the metatarsal heads.

Vaulting was suspected in 9 transfemoral amputees who constituted the $\mathrm{V}$ group. 2 amputee subjects could not be classified according to the chosen visual criterion.

\subsection{Biomechanical parameters}

The mean values and the standard deviations of each population for all considered parameters are presented in Table 1.

No statistical differences were observed between the $C$ group and the NV group for AFlexAng, AFlexPwr, KFlexAng, KFlexPwr and CoP\%. CoPX was significantly lower for the NV group compared to the $C$ group $(P=0.047)$. This indicates that amputees of the NV group showed an average position of the center of pressure during the stance farther backward in the foot anatomical frame than the control subjects ( $-29 \%$ vs $-22 \%$ ).

The $\mathrm{V}$ group showed significantly higher values for AFlexPwr, KFlexPwr, CoPX and CoP\% compared to the $C$ group and the NV group $(P<0.001)$. So amputees who vault presented a higher peak of flexion power during the contralateral single stance phase (AFlexAng $=$ $0.46 \mathrm{~W} \cdot \mathrm{kg}^{-1}$ ) and a higher dissipated power at the knee during the early stance (AFlexPwr $=-1.59 \mathrm{~W} \cdot \mathrm{kg}^{-1}$ ). Their average position of the CoP relatively to the foot frame was farther ahead ( $C O P X=-11 \%)$; furthermore the CoP moved earlier in the front part of the foot during stance phase $(\mathrm{CoP} \%=20.2 \%$ of gait cycle). KFlexAng was significantly higher for $\mathrm{V}$ group compared to $\mathrm{C}$ group $(P<0.01)$. On the contrary, values were comparable between the $V$ group and the NV group $(P=0.22)$. No differences were found between groups regarding AFlexAng.

\subsection{Review of the two non-classified amputees}

The values for the two non-classified transfemoral amputees after reviewing the video recording are presented in Table 1.

Both subjects presented a dorsi-flexion at the contralateral ankle during the contralateral single stance phase (AFlexAng $=3.4^{\circ}$ and $1.3^{\circ}$ ). The ankle flexion powers for both subjects were of the same magnitude as the average value for the $\mathrm{C}$ group and the $\mathrm{NV}$ group $\left(0.07 \mathrm{~W} \cdot \mathrm{kg}^{-1}\right.$ and $\left.0.03 \mathrm{~W} \cdot \mathrm{kg}^{-1}\right)$. The dissipated knee powers were close to the $\mathrm{C}$ group and the NV group. However, higher values for CoPX were found ( $-3 \%$ and $14 \%$ ) and lower values for CoP\% $(23 \%$ and $24 \%$ ) compared to the C group and the NV group. CoPX and CoP\% parameters for both subjects presented values comparable to the $\mathrm{V}$ group. 
Table 1

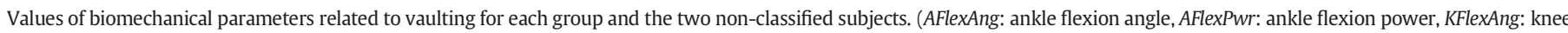

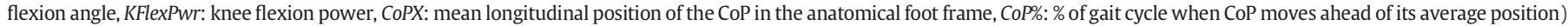

\begin{tabular}{|c|c|c|c|c|c|}
\hline \multirow[t]{2}{*}{ Mean SD [range] } & \multirow[t]{2}{*}{ Control $(C)$ group $(n=30)$} & \multirow[t]{2}{*}{ No-vaulting $(\mathrm{NV})$ group $(\mathrm{n}=6)$} & \multirow[t]{2}{*}{ Vaulting $(\mathrm{V})$ group $(\mathrm{n}=9)$} & \multicolumn{2}{|c|}{ Non classified amputees } \\
\hline & & & & 1 & 2 \\
\hline $\begin{array}{l}\text { AFlexAng } \\
\quad\left({ }^{\circ}\right)\end{array}$ & $\begin{array}{l}-1.1 \text { SD } 2.4 \\
{[-7.2 ; 2.5]}\end{array}$ & $\begin{array}{l}-1.8 \text { SD } 2.6 \\
{[-4.6 ; 1.4]}\end{array}$ & $\begin{array}{l}-2.8 \text { SD } 3.2 \\
{[-6.4 ; 4.0]}\end{array}$ & 3.4 & 1.3 \\
\hline $\begin{array}{l}\text { AFlexPwr } \\
\qquad\left(\mathrm{W} \cdot \mathrm{kg}^{-1}\right)\end{array}$ & $\begin{array}{l}-0.06 \text { SD } 0.13 \\
{[-0.35 ; 0.26]}\end{array}$ & $\begin{array}{l}-0.06 \text { SD } 0.12 \\
{[-0.27 ; 0.09]}\end{array}$ & $\begin{array}{l}0.46 \text { SD } 0.24^{\mathrm{ab}} \\
{[0.15 ; 0.93]}\end{array}$ & 0.03 & 0.07 \\
\hline $\begin{array}{l}\text { KFlexAng } \\
\left({ }^{\circ}\right)\end{array}$ & $\begin{array}{l}\text { 16.9 SD } 3.9 \\
{[9.7 ; 23.3]}\end{array}$ & $\begin{array}{l}17.4 \text { SD } 6.4 \\
{[9.7 ; 25.8]}\end{array}$ & $\begin{array}{l}22.7 \mathrm{SD} 3.8^{\mathrm{a}} \\
{[19.7 ; 32.2]}\end{array}$ & 21.1 & 20.4 \\
\hline $\begin{array}{l}\text { KFlexPwr } \\
\qquad\left(\mathrm{W} \cdot \mathrm{kg}^{-1}\right)\end{array}$ & $\begin{array}{l}-0.92 \text { SD } 0.54 \\
{[-2.24 ;-0.02]}\end{array}$ & $\begin{array}{l}-0.86 \text { SD } 0.39 \\
{[-1.36 ;-0.24]}\end{array}$ & $\begin{array}{l}-1.59 \text { SD } 0.61^{\mathrm{ab}} \\
{[-2.42 ;-0.79]}\end{array}$ & -0.70 & -0.39 \\
\hline $\begin{array}{l}\text { CoPX } \\
\quad(\% \text { foot length })\end{array}$ & $\begin{array}{l}-23 \text { SD } 5 \\
{[-32 ;-9]}\end{array}$ & $\begin{array}{l}-29 \text { SD } 2^{\mathrm{a}} \\
{[-32 ;-27]}\end{array}$ & $\begin{array}{l}-11 \mathrm{SD} 4^{\mathrm{ab}} \\
{[-16 ;-4]}\end{array}$ & -3 & -14 \\
\hline $\begin{array}{l}\mathrm{CoP} \% \\
\quad(\% \text { gait cycle })\end{array}$ & $\begin{array}{l}28.3 \text { SD } 3.6 \\
{[22 ; 36]}\end{array}$ & $\begin{array}{l}29.7 \text { SD } 3.7 \\
{[25 ; 35]}\end{array}$ & $\begin{array}{l}20.2 \text { SD } 1.6^{\mathrm{ab}} \\
{[18 ; 22]}\end{array}$ & 23 & 24 \\
\hline
\end{tabular}

a Significantly different from $C$ group $(P<0.05)$.

b Significantly different from NV group $(P<0.05)$.

\section{Discussion}

The aim of this study was to quantify vaulting of transfemoral amputees when walking on level surface. We analyzed the differences between asymptomatic subjects and two groups of amputees - with or without vaulting when categorized by clinical observations.

There was no difference in ankle flexion angle between the groups. The high variability of this parameter due to its sensitivity to anatomical landmark identification jeopardizes its use to discriminate groups. Even if vaulting is characterized by a plantar-flexion movement of the ankle, the assessment of flexion angle is not accurate enough to quantify vaulting. On the contrary, ankle flexion power appears to be a reliable parameter for vaulting quantification. This parameter is directly linked to the concentric work of muscles of the contralateral ankle (Sadeghi et al., 2000). Furthermore, all amputees presenting vaulting showed ankle flexion power values higher than $0.15 \mathrm{~W} \cdot \mathrm{kg}^{-1}$ whereas values below $0.1 \mathrm{~W} \cdot \mathrm{kg}^{-1}$ were observed for other amputees (Fig. 4) suggesting that a threshold value can be defined for a quantitative vaulting detection during clinical follow-up from conventional gait analysis. Furthermore, vaulting quantification could help in improving rehabilitation efficiency.

Significant modifications were also found at the contralateral knee for amputees showing vaulting compared with other groups. The patients of the vaulting group showed higher values of knee flexion during the beginning of the contralateral stance. Higher dissipated power at the knee during the double support in the early stance phase was also found. These results indicate a higher eccentric muscle work at the knee during the double support at the beginning of the stance phase

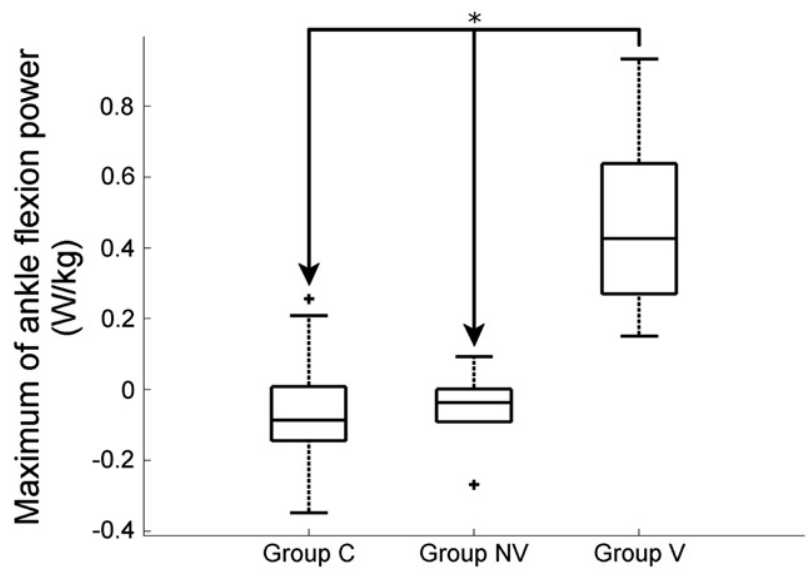

Fig. 4. Boxplot of the maximum value of ankle flexion power during the contralateral single stance support for each group.
(Perry, 1992). These modifications at the knee occurring during the loading response appeared prior to the ankle plantar flexion. The higher flexion and higher eccentric work of the contralateral knee are to prepare the vaulting movement. As already stated, the aim of vaulting is to lift the body up in order to facilitate toe clearance. This lifting is all the more effective if the maximal inclination of the tibia in the sagittal plane is reached earlier in the stance phase of gait. This anticipated progression of the tibia allows both lengthening the soleus muscle to maximize its contraction efficiency and putting the center of mass of the body ahead of the ankle joint to benefit from its plantar flexion motion. The increased knee flexion observed in the vaulting group compared with other groups can be interpreted as a consequence of the faster advancement of the tibia. At the same time, the knee joint must be stabilized by knee extensor muscles inducing an increase of the power dissipated by the joint during loading response (Perry, 1992).

Results found in the present study agree with the literature. Observations regarding kinematics and kinetics of the contralateral ankle and contralateral knee for the $\mathrm{V}$ group compared to the other groups (Fig. 5) were consistent to the results obtained by Ferrarin et al. (2012) on three children suffering from Charcot-Marie-Tooth and presenting vaulting. In spite of a small sample size, the authors reported the same association of important generated power at the contralateral ankle with a higher flexion angle and dissipated power at the contralateral knee during the early stance phase.

Results concerning CoP displacement must be observed with caution. It was hypothesized that vaulting should induce during the contralateral stance an average position of the $\mathrm{CoP}$ more towards the front part of the foot and an earlier displacement of the CoP towards the front part of the foot. Schmid et al. (2005) have analyzed CoP displacement for 12 transfemoral amputees compared to asymptomatic subjects. Anticipated longitudinal displacement of the CoP was found at the contralateral limb for transfemoral amputees by Schmid. However, they did not link the results with vaulting. It was found in the current study that vaulting is associated to an abnormal CoP displacement due to the premature heel rise. On the contrary, premature heel rise seems not to be sufficient to define vaulting as it is shown by the two non-classified subjects. The review of the video recordings did not allow reaching decision for both subjects. Due to limited video quality, it was not possible for clinicians to identify whether or not there was a premature heel rise since the elevation of the calcaneus was not as distinctive as other amputees who vault. However both patients have been observed with suspicion. Concerning calculated parameters, CoPX and CoP\% values for both subjects were close to the $\mathrm{V}$ group values indicating that the CoP was more located and moved earlier towards the front part of the foot. At the same time, positive values for AFlexAngand negative values for AFlexPwr, similar to $C$ and $N V$ group average values show that there is a dorsal flexion and dissipated power at the contralateral ankle during 

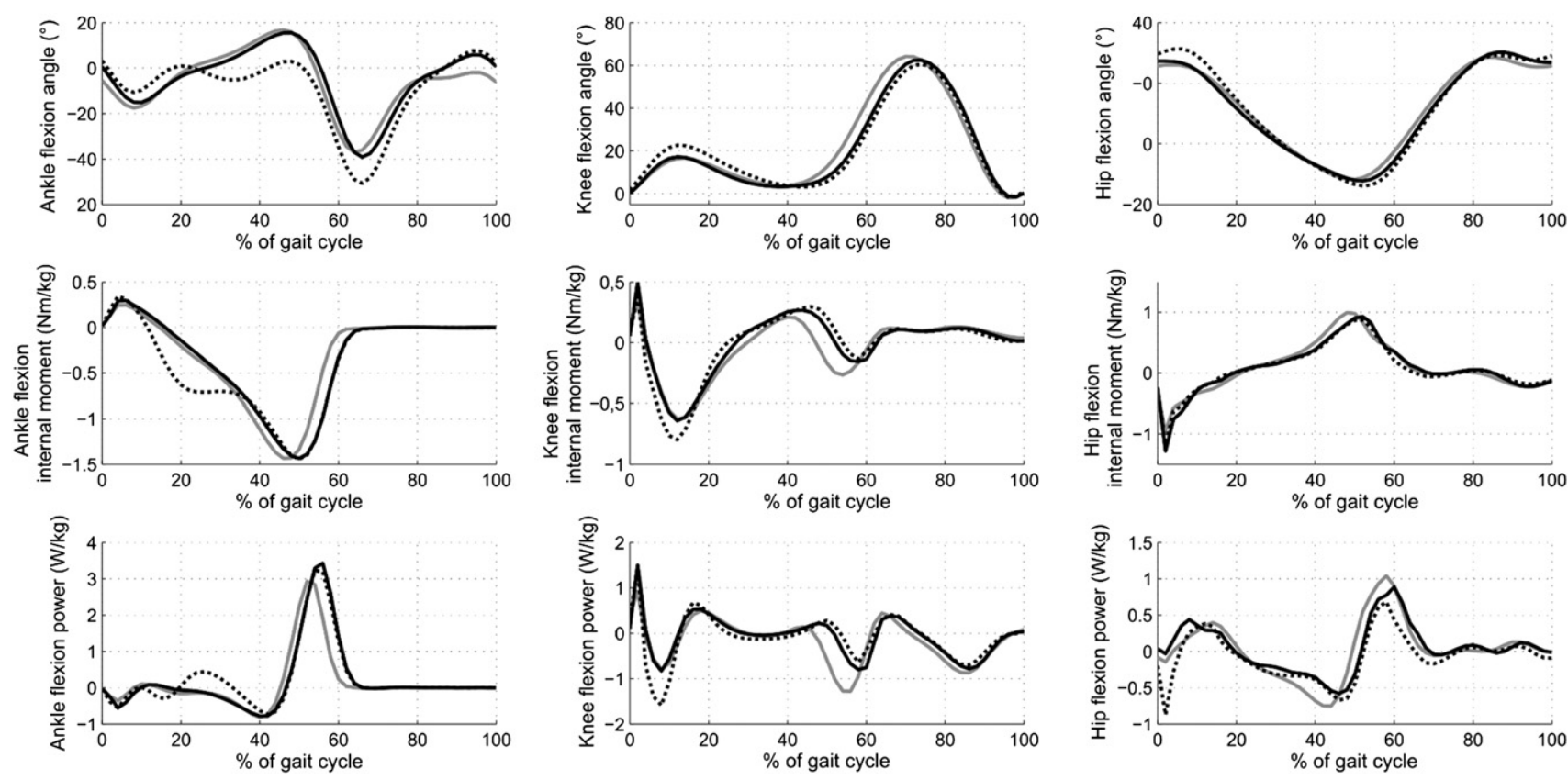

Fig. 5. Sagittal kinematics and kinetics of the control group (gray line), the no-vaulting group (solid line) and the vaulting group (dotted line).

the contralateral single stance phase. Thus, both patients seem to present a premature heel rise without propulsive movement at the ankle and so do not seem to vault. Thus, quantification of vaulting may be beneficial in reaching decisions in such cases.

Another methodological limitation lies in the sample size. The amputees were separated in two subgroups composed each of 9 and 6 subjects. Larger samples will enforce statistical analysis in further works to define threshold values of biomechanical parameters for automatic vaulting detection. However, regarding the literature and difficulties in recruiting transfemoral amputees, the 17 transfemoral amputees who participated in the current study constitute one of the biggest populations of lower-limb amputees.

\section{Conclusions}

Vaulting was analyzed for a population of transfemoral amputees using quantitative gait analysis. Transfemoral amputees who vault showed a peak in generated power at the contralateral ankle during the contralateral single stance phase. This parameter seems to be the best quantitative criterion to quantify vaulting and can be easily computed from conventional gait analysis data. Prior to this power peak, adaptations at the contralateral knee occurred which can be interpreted as a preparation of the propulsive movement at the ankle.

\section{Acknowledgments}

This study was supported by the French National Research Agency, under reference ANR-2010-TECS-020. The authors are deeply grateful to F. Lavaste, N. Martinet, J. Paysant, and N. Rapin for their contribution to the study.

\section{References}

Engsberg, J.R., Lee, A.G., Tedford, K.G., Harder, J.A., 1993. Normative ground reaction force data for able-bodied and trans-tibial amputee children during running. Prosthetics Orthot. Int. 17 (2), 83-89.

Ferrarin, M., Bovi, G., Rabuffetti, M., Mazzoleni, P., Montesano, A., Pagliano, E., Marchi, A., Magro, A., Marchesi, C., Pareyson, D., Moroni, I., 2012. Gait pattern classification in children with Charcot-Marie-Tooth disease type 1A. Gait Posture 35 (1), 131-137.

Nolan, L., Lees, A., 2000. The functional demands on the intact limb during walking for active trans-femoral and trans-tibial amputees. Prosthetics Orthot. Int. 24 (2), 117-125.

Perry, J., 1992. Gait Analysis: Normal and Pathological Function. SLACK Incorporated.

Pillet, H., Bonnet, X., Lavaste, F., Skalli, W., 2010. Evaluation of force plate-less estimation of the trajectory of the centre of pressure during gait. Comparison of two anthropometric models. Gait Posture 31 (2), 147-152.

Sadeghi, H., Allard, P., Duhaime, M., 2000. Contributions of lower-limb muscle power in gait of people without impairments. Phys. Ther. 80 (12), 1188-1196 (cited By (since 1996)17).

Sadeghi, H., Allard, P., Duhaime, P.M., 2001. Muscle power compensatory mechanisms in below-knee amputee gait. Am. J. Phys. Med. Rehabil. 80 (1), 25-32.

Schmid, M., Beltrami, G., Zambarbieri, D., Verni, G., 2005. Centre of pressure displacements in trans-femoral amputees during gait. Gait Posture 21 (3), 255-262.

Smith, D.G., Michael, J.W., Bowker, J.H., 2002. Atlas of Amputations and Limb Deficiencies. American Academy of Orthopaedic Surgeons.

Walsh, M., Connolly, P., Jenkinson, A., O'Brien, T., 2000. Leg length discrepancy-an experimental study of compensatory changes in three dimensions using gait analysis. Gait Posture 12 (2), 156-161.

Waters, R.L., Mulroy, S., 1999. The energy expenditure of normal and pathologic gait. Gait Posture 9 (3), 207-231 (cited By (since 1996) 202).

Wu, G., Siegler, S., Allard, P., Kirtley, C., Leardini, A., Rosenbaum, D., Whittle, M., D'Lima, D. D., Cristofolini, L., Witte, H., Schmid, O., Stokes, I., Standardization, \& of the International Society of Biomechanics, Terminology Committee, 2002. ISB recommendation on definitions of joint coordinate system of various joints for the reporting of human joint motion-part I: ankle, hip, and spine. International Society of Biomechanics. J. Biomech. 35 (4), 543-548.

Wu, G., van der Helm, F.C.T., DirkJan, H.E.J., Makhsous, M., Van Roy, P., Anglin, C., Nagels, J., Karduna, A.R., McQuade, K., Wang, X., Werner, F.W., Buchholz, B., Biomechanics, International Society, 2005. ISB recommendation on definitions of joint coordinate systems of various joints for the reporting of human joint motion-part II: shoulder, elbow, wrist and hand. J. Biomech. 38 (5), 981-992. 